\title{
O Trabalho como Princípio Educativo: algumas reflexões
}

\section{Work as Educational Principle: some reflections}

\author{
Ricardo Ribeiro \\ Professor do Departamento de Ciências da Educação da Faculdade \\ de Filosofia, Ciências e Letras - UNESP - Araraquara. \\ Endereço: Rodovia Araraquara-Jaú, Km I, Caixa Postal 174, CEP \\ 14800-90I, Araraquara, SP, Brasil. \\ E-mail: despertarosoløgmail.com, ricardo®fclar.unesp.br \\ I Artigo escrito a partir de palestra proferida no I Seminário ETSUS- \\ SP, outubro de 2007.
}

\section{Resumo}

Após algumas reflexões sobre o conceito de trabalho e formação, este artigo aborda algumas orientações, ou princípios, que podem contribuir para a organização de programas de formação de adultos. Ao trabalhar em programas de formação dessa natureza, devemos ter em mente que trabalhamos com indivíduos que já possuem conhecimentos elaborados, experiências práticas e vivências que devem ser consideradas como ponto de partida. Assim, devemos considerar que a aprendizagem acontece ao longo da vida, e que um curso é apenas parte do percurso de aprendizagem. $\mathrm{Ou}-$ tro aspecto importante é que programas de formação para adultos, especialmente aqueles desenvolvidos em situação de trabalho, devem ter sentido para aqueles que irão participar. Os participantes devem, portanto, aderir voluntariamente à proposta; caso contrário, ela poderá ser entendida apenas como algo imposto, e não como um ganho profissional efetivo. Nas situações de formação em situações de trabalho, é também fundamental que os programas sejam elaborados a partir de um apurado conhecimento da realidade daqueles que irão participar. Avaliar e preservar a memória do que foi realizado evita que ocorram eternos recomeços. Por fim, é fundamental que os programas de formação contem também com um programa de apoio aos participantes, de tal forma que eles se sintam mais seguros no trilhar os caminhos das mudanças, quando retornarem aos seus respectivos espaços de trabalho.

Palavras-chave: Formação de adultos; Programas de formação profissional; Educação continuada; Educação. 


\section{Abstract}

After a glance at concepts such as work and education, this article approaches some orientations or principles that can contribute to the organization of adult education courses. When we work in education programs of this nature, we must always have in mind that we are working with individuals who already have theoretical knowledge and practical experiences that must be considered as starting points. We have to consider that learning happens throughout one's life and a course is no more than part of the learning path. Another important issue when we talk about adult's education, especially those programs which are developed within work situations, is that they must have meaning for those who will be attending the course. The participants are supposed to engage in the education program voluntarily, otherwise it will be seen not as a professional gain, but as something that was imposed. It is also of great value that the course be developed based on accurate knowledge of the reality of those who will participate. Evaluating and preserving the memory of what happened during the course helps to prevent never-ending restarts. Finally, it is also important that the education courses have a suport programm, to help the participants feel safer when they start taking the changes proposed by the education program back to their real working daily lives.

Keywords: Adult Education; Professional Education Programs; Continuing Education; Education.

\section{Introdução}

De maneira geral, entendemos a educação como uma ação humana intencional com o objetivo de transmitir um conjunto específico de conhecimentos a indivíduos que supostamente não os têm. Quando se trata de pensar em educação escolar para os indivíduos mais jovens, temos supostamente um acervo conceitual extraordinário. Quando manejado com relativa habilidade, ao menos no plano do discurso, esse acervo conceitual permite que qualquer educador tenha condições para indicar os procedimentos de construção de projetos de formação relevantes. É verdade que os caminhos para essa relevância, e mesmo o entendimento do que é relevante em termos de qualidade de ensino, podem ser bem diferentes, mas quase sempre todos eles têm aspectos positivos. Entretanto, quando tratamos de educação para adultos, a situação se complica. Tratase, afinal, de uma situação em que o "outro" (ou os "outros") que deverá "aprender" alguma coisa não pode ser considerado indivíduo que "não sabe”. Não são poucas as situações em que esses indivíduos, que devem "sofrer" a formação, sabem muito mais do que aqueles responsáveis por oferecê-la.

Naturalmente, ao reconhecer essa situação, não devemos ser simplistas nem entender que as ações de formação de adultos, afinal de contas, não servem para nada. 0 reconhecimento dessa situação indica apenas que, no caso da formação de adultos, devemos considerar alguns aspectos nem sempre presentes na educação escolar para crianças, jovens e adolescentes.

\section{O Trabalho}

Ao pensarmos em "Educação pelo trabalho" ou em "Trabalho como princípio educativo", a primeira questão com a qual nos deparamos está relacionada à condição e percepção do que é trabalho. Não cabe aqui uma digressão sobre a origem do conceito trabalho, nem de todos os seus vários entendimentos através dos tempos. Pretendo apenas considerar alguns aspectos que entendo relevantes dentro do contexto da nossa reflexão.

Nas sociedades primitivas, o trabalho tinha como característica principal ser solidário e coletivo. A produção era apropriada por todos. Com o advento da economia de mercado, o trabalho deixou de ser o espaço social de construção do sentimento de tribo, 
de comunidade, passando a ser tão somente uma mercadoria que, a partir do momento em que é comprada por quem detém o capital, aliena o trabalhador da complexidade do processo de trabalho e também dos seus resultados.

Dessa forma, embora o trabalho seja responsável pela construção da nossa própria humanização, não se constitui, necessariamente, no nosso tempo em um valor humano positivo. 0 trabalho pode ser emancipador, mas pode também ser um instrumento que submete e até mesmo escraviza o ser humano. 0 trabalho pode ser responsável por gerar prazer para alguns, mas também pode ser responsável por gerar pesadelo e sofrimento para outros. E tudo isso independentemente da qualidade do trabalho ou mesmo do seu valor social ${ }^{1}$.

Outro aspecto relevante relacionado ao conceito de trabalho é que, quando fazemos referência a ele, quase sempre adotamos o conceito de "trabalho produtivo", isto é, aquele trabalho que produz um bem que tem valor de mercado, que gera ganho monetário. Assim, o trabalho doméstico é desconsiderado, resultando em grande injustiça, não exclusiva, mas especialmente, para as mulheres. A mesma coisa acontece com o trabalho realizado por membros de comunidades periféricas ou mais pobres ${ }^{2}$.

Na economia de mercado, os trabalhadores não têm controle sobre o seu trabalho. Apenas e tão somente podem vender a sua força de trabalho. Essa distinção entre trabalho e força de trabalho foi proposta por Marx, que definiu trabalho como sendo tanto o processo como o resultado do trabalho. Na economia de mercado, o trabalhador não tem controle nem sobre uma coisa, nem sobre outra. Ele não vende o produto que fez ou ajudou a fazer, isto é, o resultado do seu trabalho, assim como não tem controle sobre o processo de produção. Ao comprar força de trabalho, aquele que detém o capital utiliza-a, de acordo com seus interesses, para produzir bens com valor de mercado. 0 trabalhador pode dispor apenas de seu potencial de tempo. Vendendo o seu tempo, o trabalhador abre mão de exercer qualquer possibilidade de controle ou intervenção nas complexas relações que se estabelecem entre o indivíduo e o mundo no processo de trabalho.

Entretanto, mesmo com todas essas contradições, e ainda segundo Marx, o trabalho "é a condição indispensável da existência do homem, uma necessidade eterna, o mediador da circulação material entre o homem e a natureza" (Marx, 1987). Sendo uma "necessidade eterna”, condição de sobrevivência, estará sempre presente nas comunidades humanas, entendidas aqui nas suas várias formas ${ }^{3}$. Por isso, o trabalho é o caminho de construção da identidade, e o homem constrói a sua identidade pelo trabalho. Dessa maneira, forma-se através do trabalho e o trabalho é o princípio da sua formação.

\section{Formação}

Ajustadas agora algumas ideias sobre o entendimento do conceito trabalho, podemos refletir um pouco sobre a ideia de "Formação", que não significa apenas dar forma a algo, mas sim dar uma forma dinâmica integrando um componente artístico, cultural e intencional. Forma, como já colocavam os integrantes do movimento modernista de 1922, é coisa bem diferente de fôrma.

Trata-se de uma situação desafiadora, porque a ação formadora que integra esses três componentes - arte, cultura, intenção - deve ter como objetivo a modificação de um sistema de referências ou um modo de funcionamento de uma dada situação ou realidade. É desafiadora porque as situações de mudanças não são triviais e, embora em algumas situações as mudanças possam até acontecer com relativa rapidez, nem sempre é assim ${ }^{4}$.

\footnotetext{
O mesmo tipo de trabalho e de condições para a sua realização pode ser fonte de prazer para alguns e de tormento para outros. Construção de casas pelas próprias famílias nas favelas e nas zonas rurais, transporte rudimentar de água, agricultura de subsistência etc. 3 Cidades, países, empresas, famílias etc.

4 Um exemplo típico dessa resistência é o caso do húngaro Iguaz Semmelweis, que trabalhou no Hospital Geral de Viena entre 1844 e 1848. Diante do alto índice de febre puerperal em uma das enfermarias do hospital (maternidade), esse médico começou a desenvolver procedimentos para encontrar os motivos dessa situação. As pesquisas realizadas por Semmelweis indicaram que a causa estava relacionada ao fato de os alunos de medicina, antes de passarem pela referida enfermaria de mães que haviam acabado de dar à luz ou estavam em trabalho de parto, haviam tido aula de anatomia onde haviam feito dissecação de cadáveres. Como naquela época ainda não era plenamente aceita a ideia de que as pessoas poderiam ser contaminadas por microrganismos, os resultados da pesquisa de Semmelweis foram desconsiderados por muito tempo.
} 
Feitas essas considerações, podemos então tentar sistematizar algumas orientações que podem contribuir para a elaboração de propostas de formação profissional que partam do trabalho e que o tenham como princípio.

Antes, porém, é necessário reconhecer que a rede de quase 40 escolas técnicas do SUS já se constitui em um importante sistema de ensino profissional, com um invejável acúmulo de experiências e conhecimentos. Esse conhecimento sustenta de forma bastante satisfatória o trabalho que vem sendo desenvolvido por essas escolas. Os conteúdos das chamadas ciências da educação são apropriados e bem operados pelas equipes de educadores, profissionais da saúde e outras áreas de conhecimento envolvidas na elaboração das propostas de formação profissional das escolas técnicas do SUS.

\section{Aprendizagem ao longo da vida}

A minha primeira máquina de escrever foi-me oferecida por um vizinho que tinha um grande carinho por mim e me via como um bom aluno. Era um velho jornalista e me presenteou com a sua Remington portátil, máquina que ele havia usado por mais de 30 anos.

0 presente foi-me dado de forma solene e eu me sentia sendo entronizado em um novo mundo! Afinal, estava sendo digno da confiança de receber uma máquina de escrever. Durante muito tempo a minha mãe ficou de olho para ver se eu estava cuidando direito da Remington. Tratava-se de uma boa máquina, e poderia ter sido utilizada por outros 30 anos, se o tempo não tivesse começado a andar mais rápido do que até então era comum.

A minha fidelidade àquela belezinha foi colocada à prova quando eu conheci a famosa "IBM Esfera". Desde que conheci aquela máquina passei a tê-la como objeto de desejo. Uma das suas inovações era permitir a mudança dos tipos. As letras estavam em uma esfera que podia ser facilmente trocada e, assim, tinha-se a possibilidade de construir textos datilografados com uma apresentação muito superior à que poderia ser obtida com qualquer outra máquina de escrever. Após algum tempo, a minha fidelidade à "IBM Esfera" foi testada quando surgiu outra máquina de datilografia "eletrônica”, de marca Olivetti. Essa nova "maravilha da tecnologia" resolvia um grande problema dos documentos datilografados: o alinhamento do texto, porque tinha no seu painel uma pequena tela de cristal líquido, onde aparecia a última linha digitada, que poderia ser alinhada ou corrigida antes de ser impressa no papel.

Não consegui realizar o meu desejo nem com relação à IBM, nem com relação à Olivetti. Não só porque as minhas economias não o permitiram, mas também por causa do tempo. Em poucos meses, surgiu outra máquina eletrônica, portátil e com uma impressão de grande qualidade, e eu acabei comprando esta que, na verdade e ainda por cima, era muito mais barata do que as anteriores. Acontece, porém, que rapidamente a minha jovem e bonita máquina eletrônica também ficou velha, e eu acabei adquirindo o meu primeiro computador.

Com computadores, então, o tempo passou a correr mais rápido ainda. É impressionante como, em dois anos, aquela máquina turbinada, especial que você tem já se transformou em uma "carroça velha" movida a "lenha”, e você não sossega enquanto não compra a versão mais nova, com tela de cristal e processador "ultimum tipo"!

Situação parecida aconteceu com as atividades profissionais mais reconhecidas e valorizadas. Até os anos 196o, a formação inicial de um engenheiro, de um dentista, de um advogado era suficiente para que esse profissional exercesse a sua profissão sem se preocupar em continuar estudando, fazendo cursos ou participando de congressos. Anecessidade de formação continuada após a formação inicial não era vista como algo relevante.

Hoje, ao contrário, não é possível imaginar um profissional que não se preocupe com o estar sempre aprendendo sobre a sua área ou sobre temas que cada vez mais dialogam com áreas diversificadas. Vivemos uma realidade onde cada vez mais são valorizadas e necessárias as aprendizagens que os indivíduos "realizam ao longo das suas trajectórias pessoais, sociais e profissionais, ultrapassando as tradicionais fronteiras espaço-temporais delimitadas institucionalmente pelos sistemas de educação/formação. Num contexto

5 Não sei bem o que diferia uma máquina de datilografia elétrica de uma máquina de datilografia eletrônica, mas era assim que a máquina da Olivetti era conhecida: "eletrônica". 
de atenuação de fronteiras entre educação, formação, trabalho e lazer, o reconhecimento das aprendizagens experienciais - principalmente de adultos - constituise como um desafio incontornável aos sistemas de educação/formação nos dias de hoje.” (Pires, 2007)

Para participar criticamente das aceleradas mudanças a que assistimos hoje, e lidar com as mesmas de forma protagonista, é necessário estar atento aos saberes que podem ser adquiridos em espaços diferentes daqueles já consolidados e normatizados. "Os saberes de carácter inovador produzidos nas organizações - a partir da utilização das novas tecnologias e de novas formas de organizar o trabalho - pela acção dos actores envolvidos escapam frequentemente, pela sua natureza experiencial, aos referenciais clássicos dos saberes disciplinares. A produção e a difusão do conhecimento e, concomitantemente, a aprendizagem deixam de ser um monopólio dos sistemas de educação/formação, na medida em que ultrapassam os espaços-tempos formais, tradicionalmente delimitados e balizados pelas instâncias educativas.” (Pires, 2007)

Assim, a aprendizagem ao longo da vida desenvolvese em espaços variados (muitas vezes em situações de trabalho ou tendo o trabalho como princípio), por meio de formas distintas e sob a responsabilidade de vários e diferentes protagonistas.

\section{Adesão voluntária}

As oportunidades de formação que profissionais recebem no âmbito das suas relações de trabalho se constituem em um ganho para o empregador, mas também podem ser consideradas um ganho pessoal para os profissionais que participam. Nesse sentido, é muito importante que os profissionais possam escolher livremente se querem ou não participar de um dado programa de formação. A sua adesão voluntária possibilita um grau de compromisso que contribui, em grande medida, para um melhor aproveitamento e até mesmo para um melhor gerenciamento do programa, na medida em que este, inevitavelmente, deverá exigir dos seus participantes algum tipo de sacrifício pessoal, pelo menos no que diz respeito ao tempo. A adesão voluntária dos participantes traduz um maior compromisso por parte dos mesmos, fazendo com que eventuais sacrifícios sejam assimilados individualmente e não se transformem em problemas coletivos.

Assim, devemos sempre que possível evitar "convocações” de funcionários para programas de formação.
Os participantes potenciais devem, sim, ser informados da natureza, objetivo e das condições de desenvolvimento do trabalho de formação e, sempre que possível, devem poder escolher participar ou não.

\section{Conhecer a realidade dos participantes}

Em um dos mais bonitos filmes do Claude Lelouch, Retratos da Vida (Les Uns et les Autres), um dos personagens diz, a certa altura, que a vida são apenas quatro ou cinco histórias que se repetem. De fato, as histórias de vida são muito semelhantes e circunstâncias que fogem ao nosso controle pleno acabam determinando um sem número de histórias parecidas. Entretanto, também é verdade que, de longe, muita coisa se parece, mas de perto podemos ver que o que pareceu semelhante à distância, é muito diferente de perto.

É extremamente provável que quem trabalha na saúde há algum tempo consiga identificar as causas de um sem número de problemas (de contaminação hospitalar ao atendimento ao usuário do serviço, passando pela relação entre médicos e demais funcionários, entre outros), os quais podem ser resolvidos com relativa facilidade por meio de programas de formação profissional em serviço. Não é difícil imaginarmos programas de formação ou cursos que podem ser desenvolvidos em muitos lugares onde ocorre uma determinada situação que precisa ser alterada. Entretanto, embora os problemas sejam os mesmos ou muito parecidos, os vetores que explicam a sua incidência podem e costumam ser diferentes. É por isso muito importante que, antes de implementar programas de formação ou cursos, os seus responsáveis procurem “ouvir" com atenção as explicações ou entendimentos que os potenciais participantes têm sobre a situação que deve ser alterada. É fundamental que seja conhecido o contexto de trabalho desses potenciais participantes, porque toda organização tem uma identidade própria. Cada posto de saúde, centro de atendimento, ambulatório ou hospital tem uma cultura própria, e as relações e processos que lá ocorrem são únicos e devem ser conhecidos e reconhecidos, ampliando, assim, as possibilidades de sucesso dos programas de formação.

\section{Avaliar e preservar a memória}

Uma das políticas públicas mais importantes do Brasil é hoje desenvolvida no SUS. Decorrência da sua própria natureza essencial e do grande universo 
de beneficiários, o é também por ser uma das mais bem-sucedidas ações de descentralização de políticas públicas. Existem, naturalmente, grandes problemas, mas, comparativamente com outras políticas públicas - nos campos da educação ou da segurança, por exemplo -, é a que mais avançou. É de extrema importância que as ações de formação desenvolvidas sejam objeto de permanente e contínua avaliação, pois só assim se consegue aprimorá-las.

Embora a avaliação não seja o tema central deste artigo, é necessário fazer algumas observações. Usualmente, quando consideramos a avaliação no âmbito de situações formativas, costumamos pensar na avaliação da aprendizagem dos participantes - isto é, se os indivíduos aprenderam ou não. Embora esse seja um aspecto que obviamente merece ser considerado, é importante que a avaliação seja utilizada também em uma dimensão mais ampla. 0 aprendizado, isto é, a incorporação de novas informações que serão operadas adequadamente pelos participantes do programa, tendo em vista uma mudança, é fundamental, mas é importante que o olhar da avaliação examine as condições gerais que contribuem para que isso ocorra ou que, ao contrário, conspirem contra.

É importante que, quando for possível, sejam desenvolvidos procedimentos de avaliação no decorrer do programa, tendo em vista o seu aprimoramento ou correções de rota. A avaliação contínua, através do olhar atento à receptividade dos formandos, permite que se alterem pontos de programa e se avance com mais segurança na direção das grandes metas e direções pretendidas na ação. Também é fundamental que seja previsto um momento final de avaliação do trabalho realizado. Os instrumentos podem ser variados: formulários preenchidos pelos participantes ${ }^{6}$, uma roda de avaliação oral onde todos possam falar ${ }^{7}$, ferramentas desenvolvidas para a $W \varepsilon B^{8}$ etc.

Feita a avaliação, é muito importante que sejam preservadas as memórias da ação formativa9 ${ }^{9}$ Novos programas de formação para grupos ou organizações específicas devem ser desenvolvidos considerando o que já aconteceu naquele espaço e com aqueles indivíduos. A memória dos eventos que já aconteceram serve para alimentar as novas propostas elaboradas, e deve também ser apresentada aos participantes dos novos programas, de maneira que se tornem conscientes ou se relembrem do que já viveram, e outros conheçam o que já aconteceu naquela instituição ou naquele grupo do qual agora fazem parte.

\section{Apoiar, acolher...}

As mudanças de práticas e procedimentos não são fáceis, especialmente para adultos que vivem um tempo em que as mudanças são aceleradas, sentindo ainda o peso da ignorância ao se confrontarem com tecnologias consideradas por muitos banais. Equipamentos sofisticados e modernos são considerados superados em pouco tempo. Novos procedimentos são incorporados ao dia a dia de uma forma espantosamente rápida. Assim, quando os adultos são chamados a responder a novas necessidades e/ou práticas, nem sempre se sentem confortáveis. É normal que isso ocorra; afinal, também não tem sentido mudar apenas porque os outros querem que mudemos. A mudança, efetiva e ativa, só ocorre quando tem sentido para quem muda. Não ocorre mudança quando há submissão a uma ordem, mas sim quando há aceitação e compreensão do novo. Quando isso acontece, o novo passou a ter sentido para o indivíduo.

Além disso, o trabalho cotidiano nas organizações muitas vezes conspira contra movimentos de mudanças. Não são raras as situações em que um determinado grupo encerra uma atividade de formação estimulado e disposto a viver as mudanças necessárias, a experimentar novos caminhos. Entretanto, quando retorna às suas instituições ou aos seus espaços de trabalho, as forças conservadoras e as relações cotidianas instaladas vão, aos poucos, minando o entusiasmo inicial e fazendo com que a descrença nas possibilidades de

\footnotetext{
6 É muito importante prever esse momento na agenda do programa de formação. Não são raras as situações em que os formulários são preenchidos rapidamente ou por uns poucos participantes, perdendo-se uma importante fonte de reflexão posterior.

7 Nesses casos é muito importante preservar o registro das falas. Se for feita gravação, é muito importante que, depois, se organize a transcrição dos aspectos mais relevantes das falas.

8 IAGE - Informática Aplicada à Gestão Educacional - é um grupo de pesquisa interdisciplinar e interinstitucional que tem por objetivo geral explorar as possibilidades oferecidas pela informática para o apoio à Gestão Educacional. Embora voltado para a gestão educacional, este laboratório desenvolve ferramentas para avaliação de programas de formação de forma ágil e com grande alcance.

9 A preservação da memória deve incluir também as correspondências, circulares, material de divulgação etc.
} 
mudança tomem corpo. 0 espaço institucional, regado pelas águas que podem fertilizar o campo para que práticas novas possam brotar, vai secando, e o rio volta ao seu leito original, deixando no seu rastro apenas restos de iniciativas que poderiam ser o início de promissoras mudanças, mas que, nessa circunstância, são vistos apenas como coisas inúteis, entulhos.

Para ajudar a alimentar as forças de mudança, é importante que os programas de formação incorporem alguns procedimentos que permitam um efetivo acolhimento e apoio aos seus participantes. Depois de um curso de formação profissional que teve como objetivo oferecer aos seus participantes um novo arsenal de recursos e possibilidades, é fundamental que esses participantes possam contar com um espaço posterior de apoio e acolhimento, uma interlocução que aconteça de tempos em tempos, a possibilidade de buscar ajuda ou socializar informações e descobertas. Além de eventuais reencontros presenciais, os recursos da $W E B$ são amplos e podem ser utilizados de forma bastante criativa e estimulante. Mas é preciso que isso aconteça de fato, e que as próprias equipes e atividades de formação reconheçam o quanto a mudança em situações instaladas é complexa, e o quanto esses profissionais precisam e demandam, mesmo depois das ações de formação, apoio, incentivo, encorajamento e estímulo.

É também importante que os responsáveis pelo desenvolvimento de programas de formação procurem desenvolver ações que influenciem os espaços de trabalho dos participantes, para que estes encontrem receptividade ao retornarem às suas atividades cotidianas.
Entender “formação pelo trabalho" inclui perceber a necessidade de apoiar os profissionais no seu dia a dia, e não apenas durante as atividades e cursos de formação. Se quisermos formar profissionais ativos, dinâmicos e autônomos, conscientes das suas necessidades e prioridades, precisaremos criar situações formativas em que possam desenvolver as suas capacidades pessoais, e não apenas profissionais, de dinamismo, autonomia e decisão.

\section{Referências}

MARX, K. Manuscritos econômico-filosóficos e outros textos escolhidos. São Paulo: Nova Cultural, 1987.

PIRES, A. L. O., Reconhecimento e validação das aprendizagens experienciais: uma problemática educativa.Revista de Ciências da Educação, n. 3 . Disponível em: <http://sisifo.fpce.ul.pt>. Acesso em: 18 out. 2007 .

RIBEIRO, R. Formação de conselheiros em política pública de trabalho e renda - PPTR. In: MEHEDFF, C. G.; GARCIA, C. (org). Metodologia para formação de gestores de políticas públicas. Brasília, DF: Flasco, 2005. p. 66-88.

SENNET, R. Autoridade. São Paulo: Record, 2001.

YANNOULAS, S. (org.). Atuais tendências na educação profissional. Brasília, DF: Paralelo 15/TEM, 2001. 